\title{
The contribution of family physicians and primary care doctors to community-orientated primary care
}

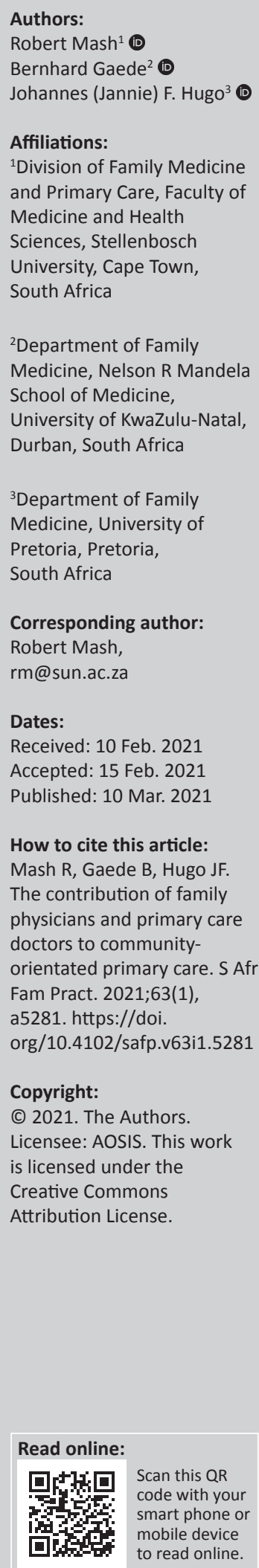

South Africa envisages a community-orientated approach to primary health care (PHC). Family physicians and primary care doctors have important roles to play in leading, implementing, supporting and maintaining community-orientated primary care (COPC). In this article, we define COPC, its key principles and approaches to implementing it in health services. Following this we describe the key competencies expected of family physicians and primary care doctors in leading and supporting its implementation; providing clinical support to the PHC teams and linking these teams to other parts of the health system, other sectors and the community. The required knowledge and skills underlying these competencies are also discussed and some specific tools included.

Keywords: primary healthcare; primary care; community orientated primary care; population health management; family physicians; general practitioners; primary care doctors.

\section{Introduction}

The primary health care (PHC) system in South Africa is organised around a commitment to community-orientated primary care (COPC). ${ }^{1}$ This means that family physicians and primary care doctors have important roles to play in leading, implementing, supporting and maintaining COPC. For many doctors this will require some re-orientation and development of new competencies.

The move towards COPC was driven by a desire to address the health needs of the whole population and not just those that access primary care facilities, with an emphasis on health promotion and disease prevention for both individuals and communities. ${ }^{1}$ South Africa invented the concept of COPC in the 1940s and exported it around the world. ${ }^{2}$ In many ways COPC embraces the core principles of a PHC approach as described in the Astana Declaration. ${ }^{3}$ Such an approach can be very cost-effective with the resources available in South Africa. ${ }^{4}$ The PHC performance initiative also describes population health management and primary care as key aspects of effective service delivery. ${ }^{5}$

This commitment to a COPC approach is seen practically through the widespread implementation of ward-based outreach teams (WBOT). ${ }^{1}$ This means that each geographically defined ward or similarly delineated community has a team of community health workers ( $\mathrm{CHWs),} \mathrm{led} \mathrm{by} \mathrm{a} \mathrm{nurse}$ and supported by a primary care doctor. As we move forward to the implementation of national health insurance, each contracting unit for PHC will need to accredit both community-based and facility-based services in a COPC framework. ${ }^{6}$ At this point all practitioners, whether in the public or private sector, will need to understand COPC.

\section{What is community-orientated primary care?}

Community orientated primary care has been defined as a continuous process by which $\mathrm{PHC}$ is provided to a defined community on the basis of its assessed health needs, by the planned integration of primary care practice and public health. ${ }^{7}$

The need for this type of integration has also been highlighted by the response to the coronavirus pandemic - where PHC teams were instrumental in home delivery of medication, ${ }^{8}$ community screening and testing ${ }^{9}$ as well as in the future vaccinations. It differs from other approaches to healthcare delivery in that it explicitly makes the link between clinical services to individuals with broader interventions at the community level. Community interventions may be in household, working, learning or social spaces. 
Nine key principles of COPC have been identified in the African region (Table 1). ${ }^{10}$

The process of analysing local health needs and assets, prioritising those needs, planning interventions and evaluating them can be seen as a COPC cycle (Figure 1). Community and stakeholder participation in this process is also essential. In the African context COPC most often involves $\mathrm{CHWs}$ as illustrated by our WBOTs.

The practical implementation of COPC has been articulated in a variety of settings locally and internationally. ${ }^{10}$ It has been used in both high- and low-income countries, in rural and urban communities and at times with interventions that

TABLE 1: Principles of community-orientated primary care.

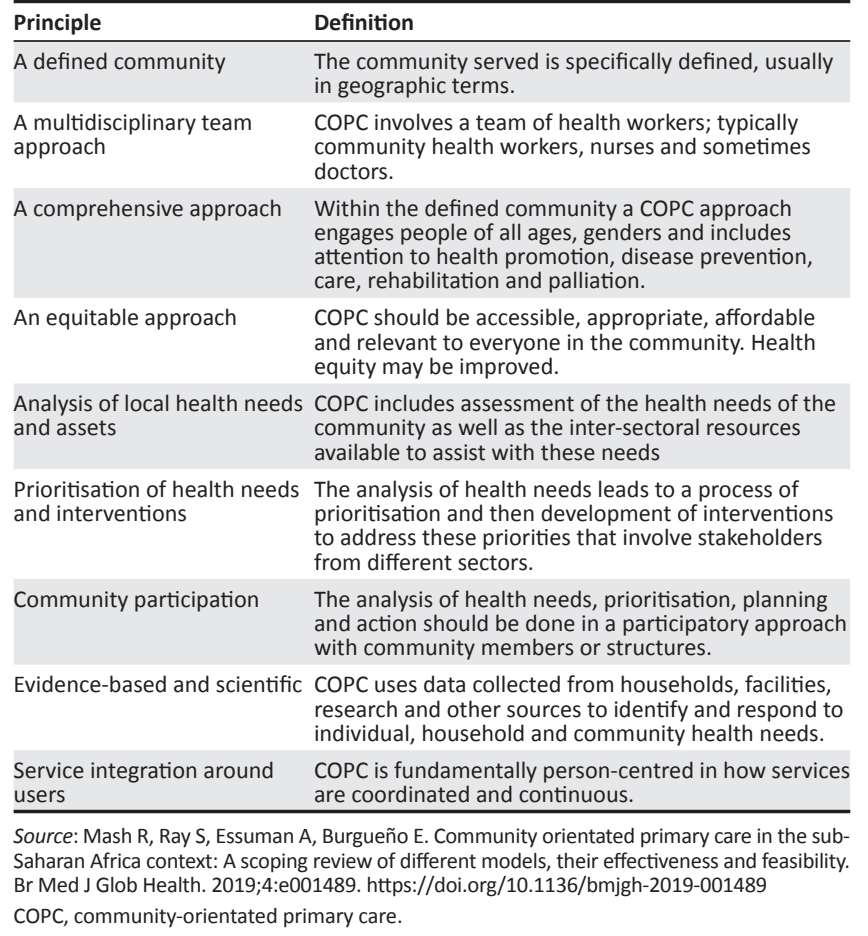

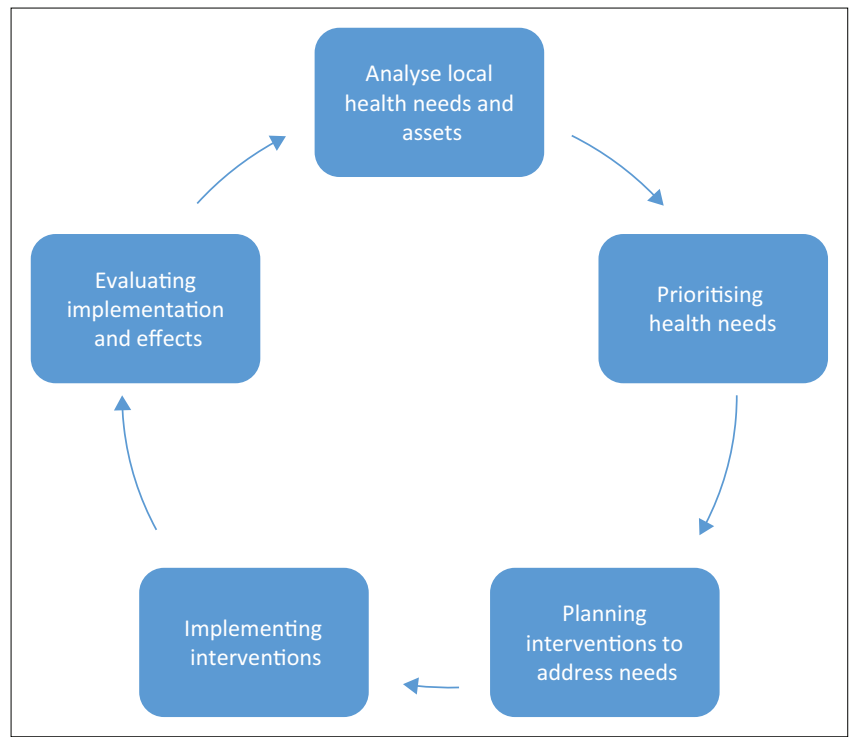

FIGURE 1: The community-orientated primary care cycle. have a particular focus such as homeless people, or followup post cardiac surgery. ${ }^{10,11}$ In South Africa large projects are being implemented amongst others in Gauteng and Cape Town. In Cape Town, for example, a 10-point framework for implementation of COPC has been adopted as shown in Figure 2 and Table $2 .{ }^{12}$ A number of training manuals on how to implement COPC have come out of the Tshwane experience $^{13,14,15}$ as well as a special collection of research studies. ${ }^{16}$

\section{Roles of the family physician and primary care doctor}

Many of the roles and competencies around COPC stretch beyond the clinical role. However, this does not negate the need for high-quality clinical services to be provided and supported. In fact, the provision of a clinical service offers powerful opportunities to transform and build stronger links with health promotion and disease prevention strategies at the household and community levels. ${ }^{17}$

\section{Lead and support the implementation of community-orientated primary care}

The current policy direction is supportive of developing COPC approaches at primary care facilities. Family physicians are often located in districts, district hospitals, sub-districts and community health centres where they can help lead the implementation of COPC with local decision makers and implementers. Primary care doctors are also in a position to help with this for the community they serve from their facility or practice. Regardless of where they are based, their responsibility stretches beyond the walls of the institution.

Practically speaking this may involve the following activities:

- Explaining the principles of COPC to other healthcare workers and managers

- Collaborating with the local management team to plan and implement COPC

- Assisting with the interpretation of data on the community's health assets and health needs. ${ }^{18}$

- Assisting with the prioritisation of health issues in the community. ${ }^{18}$

- Assisting with the planning of responses or interventions to address these health issues in the community.

- Participating in the implementation of these responses or interventions in the community.

- Assisting with the evaluation of these responses or interventions.

- Advocating for vulnerable and neglected individuals, or communities within the population served by the healthcare team.

Underlying these competencies is a need to understand and embody COPC principles, to build relationships with key role players, to analyse and interpret data, to facilitate prioritisation processes such as the nominal group technique (see Box 1), to facilitate rational planning processes and design of interventions as well as plan their evaluation. Design of projects may require the ability to 
TABLE 2: The Cape Town framework for implementation of community-orientated primary care.

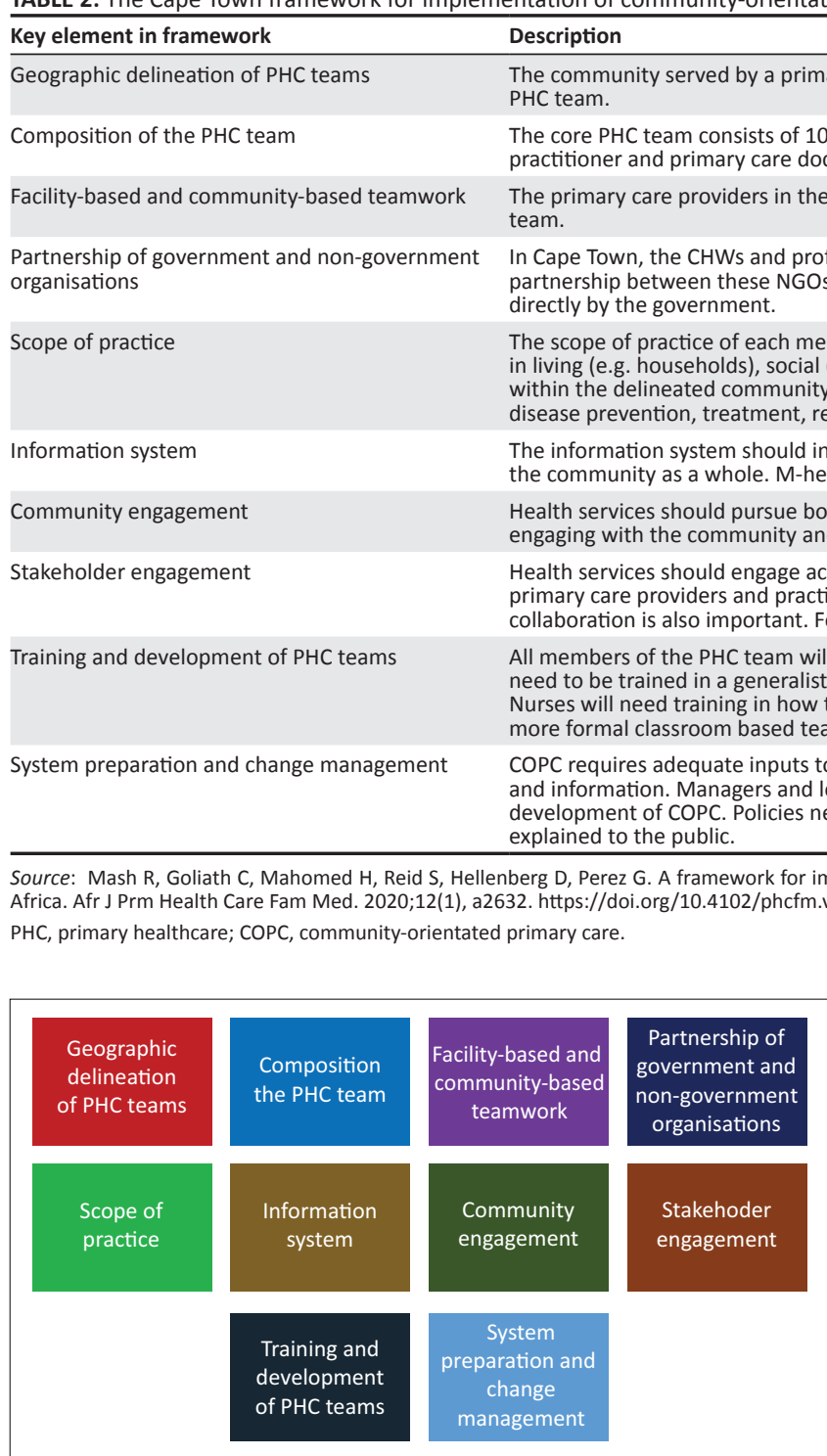

PHC, primary healthcare.

FIGURE 2: Elements of the framework to implement community-orientated primary care in Metro Health Services, Cape Town.

clarify the logic behind the project that is expected to lead to change (see Figure 3). Such a logic model can be used to plan evaluation of the intervention. Implementation science may be of particular use with a mixed-methods approach to evaluating a range of implementation outcomes (see Box 2). ${ }^{19}$ Mixed methods implies the collection of both quantitative data (e.g. routinely collected, a simple survey) as well as qualitative data (e.g. interviews) to evaluate implementation. In addition there will be measures of the expected effects or effectiveness (outputs and outcomes) that need to be collected, although these may take longer to change.

\section{Provide support to the primary healthcare teams in your community}

As a clinician you will be used to providing support to more junior doctors, nurse practitioners and others in your facility. With a COPC approach such support extends to the
BOX 1: Nominal group technique for prioritisation of ideas.

Step 1 - Silent phase: Give each member of the group a piece of A4 paper on which is written the specific question that you want them to think about. Ask them to write down as many ideas or responses as they can to the question. Each person should work alone and in silence for 15-20 min.

Step 2 - Item generation, or round-robin phase: Form people into sub-groups of five or six and have each one elect a scribe. Each person then reads out one idea/ response, which the scribe records on a flip chart, until all the ideas are recorded. This ensures equal participation from everyone. No discussion or comment the ideas is allowed at this stage.

Step 3 - Item clarification phase: Each sub-group discusses the items recorded to ensure that the meaning is clear and shared by all. They can combine or edit items that duplicate or overlap, but they should not discard any items. At the end items that duplicate or overlap, but they should not discard any items.
of this process, they should create a clearer and shorter list of items.

Step 4 - Voting phase: Each person must choose five items from the list that are most important to him and rank them in order of priority on a scale of 5 (most important) to 1 (least important). They write down their selection and ranking on a voting paper, all of which are then collected. Compile all the prioritised items from each sub-group into a master list, although not in rank order.

Step 5 - Reassembly of group phase: The entire group now repeats steps 3 and 4 for the master list. Collect the final voting papers and analyse them to give a final ranking of the items that the group has prioritised.

Source: Buso D, Reid S. How to make a community diagnosis and prioritise health issues. In: Mash B, Blitz J, editors. South African family practice manual. 3rd ed. Pretoria: Van Schaik, 2015; p. 497-500.

community-based nurses and CHWs. Community health workers may refer patients to you for help in the facility or in the community. At times this may necessitate a home visit to support the PHC team if, for example, the patient is complicated and housebound. ${ }^{20}$

Family physicians usually take responsibility for leading clinical governance along with the rest of the team. ${ }^{21}$ Clinical governance focuses on the quality of care and patient safety. In a COPC approach, this responsibility extends to the whole PHC team and not just care in the facility. It therefore includes the clinical governance processes for the care in the home, the quality of the referral system and the inclusion of services such as rehabilitation or palliative care. Clinical governance activities may include: 


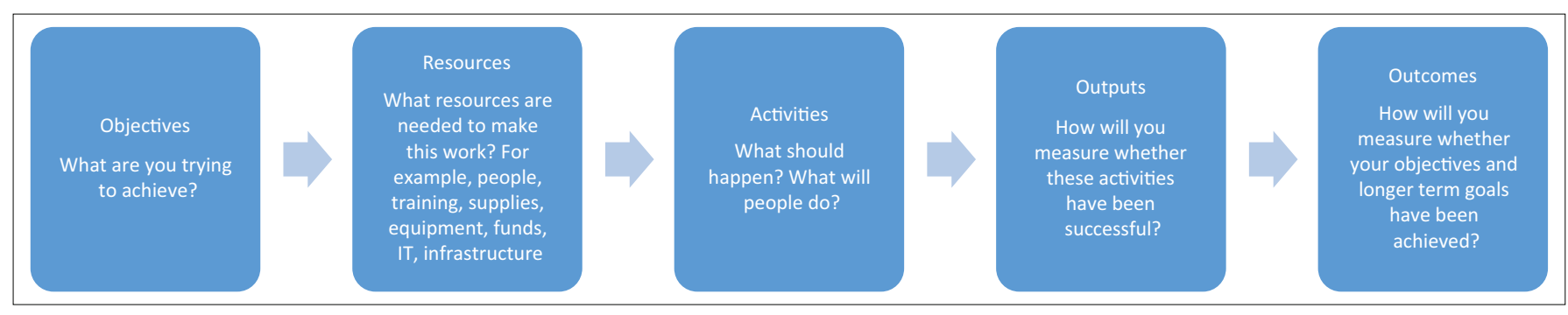

IT, information technology.

FIGURE 3: A logic model approach.

\section{BOX 2: Implementation outcomes.}

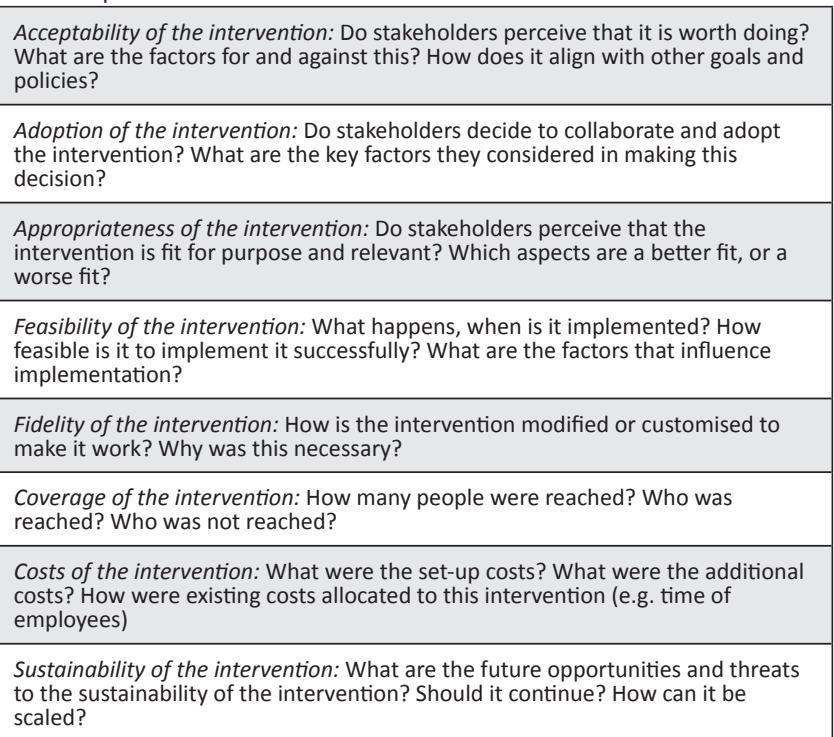

Source: Adapted from Peters DH, Adam T, Alonge O, Agyepong IA, Tran N. Implementation research: What it is and how to do it. Br Med J [serial online]. 2013 [cited 2019 Apr 5] 347:f6753. Available from: https://www.bmj.com/content/347/bmj.f6753

- Training of other healthcare workers

- For example, training CHWs in use of personal protective equipment or screening for the coronavirus disease 2019 (COVID-19), responding to problems or challenges that arise from practice

- Clinical audit and feedback

- For example, quality of active surveillance for tuberculosis (TB) in the community ${ }^{22}$

- Facilitating reflection on health information

- For example, the analysis of household assessment data collected by $\mathrm{CHWs}^{23}$

- Implementation of new guidelines

- For example, how CHWs can calculate cardiovascular risk with non-laboratory data ${ }^{24}$

- Review and appraise new evidence for the team

- For example, value of home delivery of medication by $\mathrm{CHWs}^{25}$

- Participating in research to address questions that arise from practice

- For example, what is the role of CHWs in noncommunicable diseases

These activities also imply a wide range of underlying knowledge, skills and attitudes. Creating a learning environment is important to continuously improve and to train or teach effectively. ${ }^{26}$ The ability to analyse and interpret data, appraise evidence and sometimes create new evidence is also key.

\section{Link the primary healthcare teams to the rest of the health system, other sectors and community}

The family physician and primary care doctor should pay particular attention to the coordination of care within and between PHC teams. For example, help in building a strong relationship between facility-based and community-based members of the PHC team, to coordinate care for the patients. The introduction of home delivery of medication by CHWs during COVID-19, for example, necessitated much closer cooperation between clinicians, pharmacists, nurses and CHWs. ${ }^{8}$

Family physicians and doctors may also be a strong link between the PHC team and the local district hospital, or higher levels of care. Multidisciplinary ward-rounds can include members of the PHC team and improve coordination of care for patients as well as improve the understanding of the hospital teams in the context of the community. It is important that each hospital, health centre and clinic has a specific plan to link COPC practice to care in the institution. This is in the form of care-coordination ward rounds, multidisciplinary patient and family discussions, well-structured referral letters, discharge summaries and patient retained records. In some hospitals a team of CHWs and a WBOT team leader works full time in the hospital to facilitate the coordination of care. This should be facilitated and supported by the family physicians and other doctors.

Family physicians and doctors should also use their leadership positions to build relationships with other sectors, particularly social services. Health and social services often go hand-in-hand and require mutual linkages and collaboration. Other sectors may be important depending on the prioritised needs of the community. For example, concern for illegal circumcision schools or crime and violence may need links to the police and neighbourhood watch, whilst concern for teenage pregnancy may need links to the educational sector. As mentioned above, this often involves a range of advocacy skills. ${ }^{27}$

Family physicians and doctors should also use their leadership positions and authority to build relationships with formal and informal community structures. Participating in local community health forums may enable community engagement and participation in the COPC cycle. 
Whilst such coordination and relationship building is not the sole responsibility of the family physician or other doctors, they are in a powerful position to offer leadership alongside managers and senior health professionals.

\section{Conclusion}

South Africa has moved towards a COPC approach to providing health services, which has tremendous potential for improving the health of communities. Family physicians and primary care doctors need to understand and embody the principles of this COPC approach so that they can help lead the health services in this direction. They will also need to provide clinical support and clinical governance to the whole PHC team engaged in COPC. They can also be instrumental in coordinating care within and between levels of the health system, supporting community and stakeholder engagement. These various roles and activities require an expanded knowledge base and skills-set, beyond the traditional clinical roles.

\section{Acknowledgement Competing interests}

The authors have declared that no competing interests exist.

\section{Authors' contributions}

R.M. wrote the initial draft, which was revised and edited by B.G. and J.H. All authors approved the final version.

\section{Disclaimer}

The views and opinions expressed in this article are those of the authors and do not necessarily reflect the official policy or position of any affiliated agency of the authors.

\section{References}

1. Matsoso M, Fryatt R, Andrews G. The South African health reforms, 2009-2014: Moving towards universal coverage [homepage on the Internet]. Cape Town: Juta; 2015 [cited 2018 Dec 18]. Available from: https://scholar.google.co.za/ scholar?hl=en\&as_sdt $=0 \% 2 \mathrm{C} 5 \& \mathrm{q}=$ South-African-Health-Reforms-20092014\&btnG $=$

2. Keegan $\mathrm{K}$, Tollman S. A perspective on primary health care in South Africa: Primary health care: In context. In: South African health review [homepage on the Internet]. Cape Town: Health Systems Trust, 2008 [cited 2018 Apr 3]; p. 17-30. Available from: https://journals.co.za/content/healthr/2008/1/EJC35514

3. World Health Organization. Astana declaration on primary health care [homepage on the Internet]. 2018 [cited 2018 Dec 18]. Available from: https://www.who.int/ primary-health/conference-phc/declaration
4. Daviaud E, Besada D. Saving lives, saving costs: Investment case for community health workers in South Africa. South African Medical Research Council: Pretoria; 2017.

5. Primary health care performance initiative [homepage on the Internet]. [cited 2018 Apr 18]. Available from: https://improvingphc.org/phcpi-conceptual-framework

6. Department of Health. National Health Insurance in South Africa: Policy paper. Pretoria: Department of Health; 2011.

7. Abramson J. Community-oriented primary care - Strategy, approaches, and practice: A review. Public Health Rev. 1988;16(1-2):35-98.

8. Brey Z, Mash R, Goliath C, Roman D. Home delivery of medication during coronavirus disease 2019, Cape Town, South Africa: Short report. Afr J Prim Health Care Fam Med. 2020;12(1):a2449. https://doi.org/10.4102/phcfm.v12i1.2449

9. David N, Mash R. Community-based screening and testing for coronavirus in Cape Town, South Africa: Short report. Afr J Prim Health Care Fam Med. 2020;12(1):a2499. https://doi.org/10.4102/phcfm.v12i1.2499

10. Mash R, Ray S, Essuman A, Burgueño E. Community orientated primary care in the sub-Saharan Africa context: A scoping review of different models, their org/10.1136/bmjgh-2019-001489

11. Thomas Gavagan T. A systematic review of COPC: Evidence for effectiveness. Health Care Poor Underserved. 2008;19(3):963-980. https://doi.org/10.1353/ hpu.0.0061

12. Mash R, Goliath C, Mahomed H, Reid S, Hellenberg D, Perez G. A framework for implementation of community orientated primary care in the Metro Health Services, Cape Town, South Africa. Afr J Prm Health Care Fam Med. 2020;12(1) a2632. https://doi.org/10.4102/phcfm.v12i1.2632

13. Marcus T. A practical guide to doing community oriented primary care. Pretoria: Minuteman Press, 2015; p. 210.

14. Marcus T. Community oriented primary care. Cape Town: Pearson, 2013; p. 290.

15. Bam N, Marcus T, Hugo J, Kinkel H.-F. Conceptualizing community oriented primary care (COPC) - The Tshwane, South Africa, health post model. Afr J Prim Health Care Fam Med. 2013;5(1):a423. https://doi.org/10.4102/phcfm.v5i1.423

16. PHCFM. COPC-based integrated district health system: Special collection Original research. Afr J Prim Health Care Fam Med [serial online]; 2020 [cited 2021 Jan 28]. Available from: https://phcfm.org/index.php/phcfm/browseSearch/ sections/view?sectionld $=23$

17. Gaede B. Revisiting the doctor's role at the primary healthcare clinic. S Afr Fam Pract. 2020;62(1):a5242. https://doi.org/10.4102/safp.v62i1.5242

18. Buso $D$, Reid $S$. How to make a community diagnosis and prioritise health issues. In: Mash B, Blitz J, editors. South African family practice manual. 3rd ed. Pretoria: Van Schaik, 2015; p. 497-500.

19. Peters DH, Adam T, Alonge O, Agyepong IA, Tran N. Implementation research: What it is and how to do it. Br Med J. 2013;347:f6753. https://doi.org/10.1136/ bmj.f6753

20. Reid S. How to do a home visit. In: Mash B, Blitz J, editors. South African family practice manual. 3rd ed. Pretoria: Van Schaik, 2015; p. 494-496.

21. Mash R, Blitz J, Malan Z, Von Pressentin K. Leadership and governance: Learning outcomes and competencies required of the family physician in the district health
system. S Afr Fam Pract. 2016;58(6):232-235. https://doi.org/10.1080/20786190 system. S Afr Fam
.2016 .1148338

22. Ajudua FI, Mash RJ. Implementing active surveillance for TB - The views of managers in a resource limited setting, South Africa. PLoS One. 2020;15(10):e0239430. https://doi.org/10.1371/journal.pone.0239430

23. Mash R, Du Pisanie L, Swart C, Van der Merwe E. Evaluation of household assessment data collected by community health workers in Cape Town, South Africa. S Afr Fam Pract. 2020;62(1):a5168. https://doi.org/10.4102/safp.v62i1.5168

24. Gaziano TA, Abrahams-Gessel S, Denman CA, et al. An assessment of community health workers' ability to screen for cardiovascular disease risk with a simple, noninvasive risk assessment instrument in Bangladesh, Guatemala, Mexico, and South Africa: An observational study. Lancet Glob Health. 2015/3(9):e556-e563. https://doi.org/10.1016/S2214-109X(15)00143-6

25. Louw JM, Rantloane B, Ngcobo S, et al. Home delivery of medication as part of reducing congestion in primary healthcare in Tshwane District Health Services. $S$ Afr J Public Health. 2020;4(2):50. https://doi.org/10.7196/SHS.2020.v4.i2.124

26. Mash B, Edwards J. Creating a learning environment in your practice or facility. $S$ Afr Fam Pract. 2020;62(1):a5166. https://doi.org/10.4102/safp.v62i1.5166

27. Rural Health Advocacy Program. Voice - A health care provider's guide to reporting healthcare challenges: Principles, tools \& strategies [homepage on the Internet]. [cited $2021 \mathrm{Feb} 2$ 2]. Available from: http://rhap.org.za/wp-content/ uploads/2017/05/RHAP-Voice-Manual-V2_2017-1.pdf 